Published by Al-Nahrain College of Medicine P-ISSN 1681-6579

E-ISSN 2224-4719

Email: iraqijms@colmed-alnahrain.edu.iq http://www.colmed-alnahrain.edu.iq http://www.iraqijms.net

\title{
Localization of Tight Junctions between Tanycyte-Like Cells of the Sulcus Medianus Organum in Rat Brain
}

\author{
Fadhil H. Ahmed ${ }^{1}$ BVM\&S, Muthanna A. Al-Kaabi ${ }^{1} P h D$, Sarmad E. Al-Marsoummi ${ }^{1}$ MSc, Hayder \\ A. Al-Aubaidy ${ }^{2} P h D$
}

${ }^{1}$ Dept. of Human Anatomy, College of Medicine, Al-Nahrain University, Baghdad, Iraq, School of Medicine, Faculty of Health, University of Tasmania, Australia

\begin{abstract}
Background Tanycytes are highly specialized ependymal cells (ECs) that line the regions of circumventricular organs (CVOs) where the blood-brain barrier is absent. These cells show tight junctions (TJs) that form a blood-cerebrospinal fluid barrier at the regions of these organs, thus modulating the transport mechanisms between the cerebrospinal fluid and the brain capillaries.

Objective To investigate the presence of TJs between ECs of the sulcus medianus organ (SMO) in the floor of the $4^{\text {th }}$ ventricle in comparison to the region of the median eminence (ME) of the hypothalamus, a known CVO in the brain.

Methods Ten adult male rats (Rattus Norvegicus Albinus) aged 3-6 months were used to study the general histological morphology of ECs at the SMO and ME regions by $\mathrm{H}$. and E. stain, and to explore the immunofluorescence labelling of these cells for TJs using anti-ZO1 FITC.

Results The ECs were arranged in 2-3 layers in the depth of the median sulcus (MS) at the SMO region as seen with $\mathrm{H}$. and E. stain. Immunofluorescent labelling with anti-ZO1 FITC revealed the presence of TJs between ECS of the SMO in a way similar to that reported between tanycytes of the ME.

Conclusion The SMO contained tanycytes or tanycyte-like cells that exhibited TJ complexes. This unique cell population added a strong evidence for the presence of a CVO in the rostral part of the MS to link CVOs on both sides of the cerebral aqueduct.

Keywords Tanycytes, circumventricular organs, sulcus medianus organum, tight junctions

Citation Fadhil H. Ahmed, Muthanna A. Al-Kaabi, Sarmad E. Al-Marsoummi, Hayder A. Al-Aubaidy. Localization of tight junctions between tanycyte-like cells of the sulcus medianus organum in rat brain. Iraqi JMS. 2017; Vol. 15(1): 48-63. doi: 10.22578/IJMS.15.1.7
\end{abstract}

List of abbreviation: $A P=$ Area postrema, $B B B=$ Blood-brain barrier, BCSFB = Blood-CSF barrier, CNS = Central nervous system, CSF $=$ Cerebrospinal fluid, $\mathrm{CVOS}=$ Circumventricular organs, $\mathrm{ECS}=$ Ependymal cells, $\mathrm{ME}=$ Median eminence, $\mathrm{MS}=$ Median sulcus, $\mathrm{NH}=$ Neurohypophysis, OVLT = Vascular organ of the lamina terminalis, $\mathrm{Pi}=$ Pineal gland, $\mathrm{SCO}=$ Subcommissural organ, $\mathrm{SFO}=$ Subfornical organ, $\mathrm{SMO}=$ Sulcus medianus organum, $\mathrm{TJ} \mathrm{s}=$ Tight junctions, $\mathrm{ZO} 1=$ Zonula occludens-1

\section{Introduction}

$\mathrm{n}$ the rat brain, neuroepithelial cells form ependymal cells (ECs) before day 10 of embryonic development and start to proliferate after the neural plate formation (1). Altman and Bayer ${ }^{(2,3)}$ observed that ependyma was first formed on day 16 of embryonic development but reported that it was not completed in some regions until the second postnatal week. In addition, the bulk of common ECs within the cerebral ventricles form on embryonic days 16-18, however, the specialized tanycytic epithelium is generated mainly postnatally.

Horstmann ${ }^{(4)}$ was the first to describe that the elongated bipolar ependymal cells lining the infundibular recess of the $3^{\text {rd }}$ ventricle had their proximal pole in the ventricular wall and 
the distal pole contacting the pituitary portal vessels. Because of their shape, Horstmann called these cells "tanycytes" (Greek tanus, "elongated"). Tanycytes that line the $3^{\text {rd }}$ ventricle do not comprise a homogenous cell population; four different types of tanycytes have been described based on their location, morphology, cytochemistry, ultrastructure, and function ${ }^{(5)}$. Tanycytes have been reported on the floor of the $4^{\text {th }}$ ventricle as well as on the walls and floor of the $3^{\text {rd }}$ ventricle, but few data are available regarding tanycytes of the cerebral aqueduct ${ }^{(6)}$.

Circumventricular organs (CVOs) are small structures bordering the median ventricular cavities in the brain which share common morphological and endocrine-like characteristics that distinguish them from other parts of the nervous system. Some of their unique features are cellular contacts with two fluid compartments, blood and cerebrospinal fluid (CSF), in addition to neural connections with strategic brain nuclei to form circuits for communications throughout the neural pathways ${ }^{(7)}$. These specialized areas are points of integration between the blood, the brain parenchyma, and the CSF ${ }^{(8)}$.

Most of the brain's CVOs (median eminence (ME), neurohypophysis (NH), vascular organ of the lamina terminalis (OVLT), subfornical organ (SFO), pineal gland $(\mathrm{Pi})$, subcommissural organ (SCO), are located at various positions in the wall of the $3^{\text {rd }}$ ventricle, while the area postrema (AP) is situated in the wall of the $4^{\text {th }}$ ventricle ${ }^{(9)}$.

The most fascinating part of the vascular morphology in CVOs is the capillary vessels having fenestrated endothelial cells in all CVOs aside from the SCO ${ }^{(10)}$. Thus, the blood-brain barrier (BBB) is lacking in all except one: the SCO and, unlike many regions of the brain, there can be bidirectional movement of polar particles between the blood and the neural environments of the CVOs. Nevertheless, there are variations in the barrier properties of each of the CVOs, with the ME and AP expressing less proteins related to endothelial tight junctions than SFO, OVLT and SCO (11-13), thus allowing more access of circulating polar particles into and out of the interstitium. The mammalian CVOs subdivided into two groups. One group, comprised of the SCO and choroid plexus, is characterized by modified or vascularized ECs. The second group, comprised of the SFO, OVLT, NH, ME, Pi, and AP, is characterized by subependymal elements, which differ from the ECs. This second group has been further categorized into sensory (SFO, OVLT, and $A P$ ) and secretory CVOs (NH, ME, and $\mathrm{Pi}$ ) (7).

In CVOs where exchange between the specialized neurons and the blood needs to be maintained (neuropeptide secretion to blood; chemosensitivity to monitor blood composition), the capillary endothelium is permeable, but these regions do not form a 'leak' across the BBB, by virtue of tight junctions between specialized ECs in CVOs, and between the processes of tanycytes and astrocytes glia that isolate the CVOs from brain parenchyma (14).

The specialized ECs (tanycytes) of these brain areas, are connected by tight junctions (TJs) between their apices, near their ventricular surface. The hemal milieu of the perivascular spaces and the CSF-milieu of the ventricle are here distinctly separated by the apical TJs of the tanycytes ${ }^{(15)}$.

The TJs protein zonula occludens-1 (ZO1) is expressed by ECs as opposed to fenestrated endothelial cells, suggesting that the barrier has been shifted from the vascular to the ventricular side. Therefore, blood-CSF barrier (BCSFB) is composed of the choroid plexus epithelial cells (ependyma) while the endothelial BBB is composed of the highly specialized central nervous system (CNS) microvascular endothelial cells. These barriers prevent paracellular diffusion of destructive elements into the CNS by presence of highly complex TJs of the BCSFB and BBB, which maintain brain homeostasis ${ }^{(16,17)}$.

Collins ${ }^{(18)}$ in 1989 was the first to describe a CVO in the region of the median sulcus (MS) of 
the $4^{\text {th }}$ ventricle in the rabbit where she designated it as the sulcus medianus organum (SMO). Since then, little attention was paid for the investigation of this organ. The ECs cells in this region are predominantly nonciliated. The apical surface of each cell has characteristic microvillous projections with pinocytotic vesicles. The cell body is elongated, with basal process. The general morphology of the cells is similar to tanycytes found in other CVOs. However, no immunohistochemical studies were done on the SMO to demonstrate TJs complexes between ECs of this region to add an evidence for the existence of a CVO in the rostral part of the MS.

This work targets the immunohistochemical proof for the presence of tanycytes or tanycyte-like cells in the region of the SMO. General histological staining and fluorescence immunohistochemical labelling were used to achieve this goal.

\section{Methods}

\section{Animals and tissue preparation}

A sample of 10 adult male rats (Rattus Norvegicus Albinus) aged 3-6 months were taken from the animal house of the High Institute for Infertility Diagnosis and Assisted Reproductive Technologies - Al-Nahrain University during the years 2015-2016 on basis of being apparently active and healthy, with $300 \pm 50$ g body weight. Animals were kept on fresh trefoil diet for 2 weeks prior to dissection. Animals were euthanized with chloroform impregnated cotton wool in an air tight chamber for 5 minutes. Then, skull dissection was done to deliver the brain into and fixed in $10 \%$ neutral buffer formalin (NBF) (Fisher scientific $\left.^{\otimes}\right)$ for 36 hours in preparation for dissection into two parts under dissecting lens, one part contained the $\mathrm{ME}$ and the other part included the cerebellum, $4^{\text {th }}$ ventricle and SMO.

Standard processing procedures were performed with Analar ${ }^{\circledR}$ materials and $5 \mu \mathrm{m}$ thickness section were cut from the regions of the SMO and ME with a Richert-Jung ${ }^{\circledR}, 2030$ MOT Biocut microtome.
Hematoxylin and Eosin (H. \& E.) staining

Harris modified hematoxylin (Riedel-de Haen ${ }^{\circledR}$ ) and Eosin-Y (Fisher scientific ${ }^{\circledR}$ ) were prepared according to Suvarna et al. ${ }^{(19)}$.

\section{Immunohistochemical staining:}

\section{Antigen retrieval}

Hydrated slides were processed for antigen retrieval as follows: Slide were put in a Coplin jar containing sodium citrate buffer (antigen retrieval solution) which was prepared according to Shi et al. (20):

- Solution A: (10.505 g) of Citric acid monohydrate dissolve in $500 \mathrm{ml}$ of distilled water (0.1 M)

- Solution B: (14.704 g) of Sodium citrate dissolve in $500 \mathrm{ml}$ of distilled water (0.1 M)

Mix $9 \mathrm{~mL}$ of solution $\mathrm{A}+41 \mathrm{~mL}$ of solution $\mathrm{B}$. Then the Coplin jar was transferred to an autoclave $\left(120^{\circ} \mathrm{C}, 1.2 \mathrm{Bar}\right)$ for 30 minutes and left to cool down to room temperature for 20 minutes. Slides were washed in running tap water for 5 minutes, distilled water for 5 minutes, Tris buffer-Tween 20 for 5 minutes and finally rinsed 3 time with Tris buffer.

\section{Antibody labelling}

Tissue sections were then "ringed" using wax pen, rinsed 3 times in Tris buffer and incubated in a humid chamber with the primary antibodies for 2 hours at room temperature $\left(25^{\circ} \mathrm{C}\right)$. The primary antibodies were diluted (1:100) in Tris buffer. Rabbit anti-Zo1 primary antibodies were pre-conjugated with FITC (Biorbyte ${ }^{\circledR}$ ) where they needed no further labelling procedure.

\section{Controls}

Negative control was prepared by staining sections from the regions of SMO and $M E$, in addition to kidney sections in the same staining producer except for the omission of the primary antibody.

Positive control was prepared by using kidney sections stained with anti-ZO1 antibodies in the same producer. 


\section{Examination of slides}

Examination of slides stained with H\&E was done under light microscope (Richert-Jung ${ }^{\circledR}$ Polivar) with $4 \mathrm{X}, 10 \mathrm{X}$ and $40 \mathrm{X}$ objective lenses and photographed with Nikon $\mathrm{D} 3000^{\circledR}$ digital camera.

Those slides labelled with (anti-ZO1-FITC) were examined with fluorescent microscope (AXIOZEISS $\left.{ }^{\circledR}\right)$. Two UV filters were used: FITC filter (519 nm), and DAPI filter (435 nm) for bright green, and blue fluorescence, respectively.

\section{Ethical statement}

All applicable international, national, and/or institutional guidelines for the care and use of animals were followed. All procedures performed in studies involving animals were in accordance with the ethical standards of the institution or practice at which the studies were conducted.

\section{Results}

General morphology with H. \& E. staining Median eminence

The ME, located at the ventral side of the $3^{\text {rd }}$ ventricle, was lined with a single layer of ECs similar to those lining the cerebral ventricles elsewhere. The nuclei of these cells stained blue-violate in color while their cytoplasm stained pink. No specific features could be identified with H. \& E. staining to mark these ECs as tanycytes (figures 1 and 2).

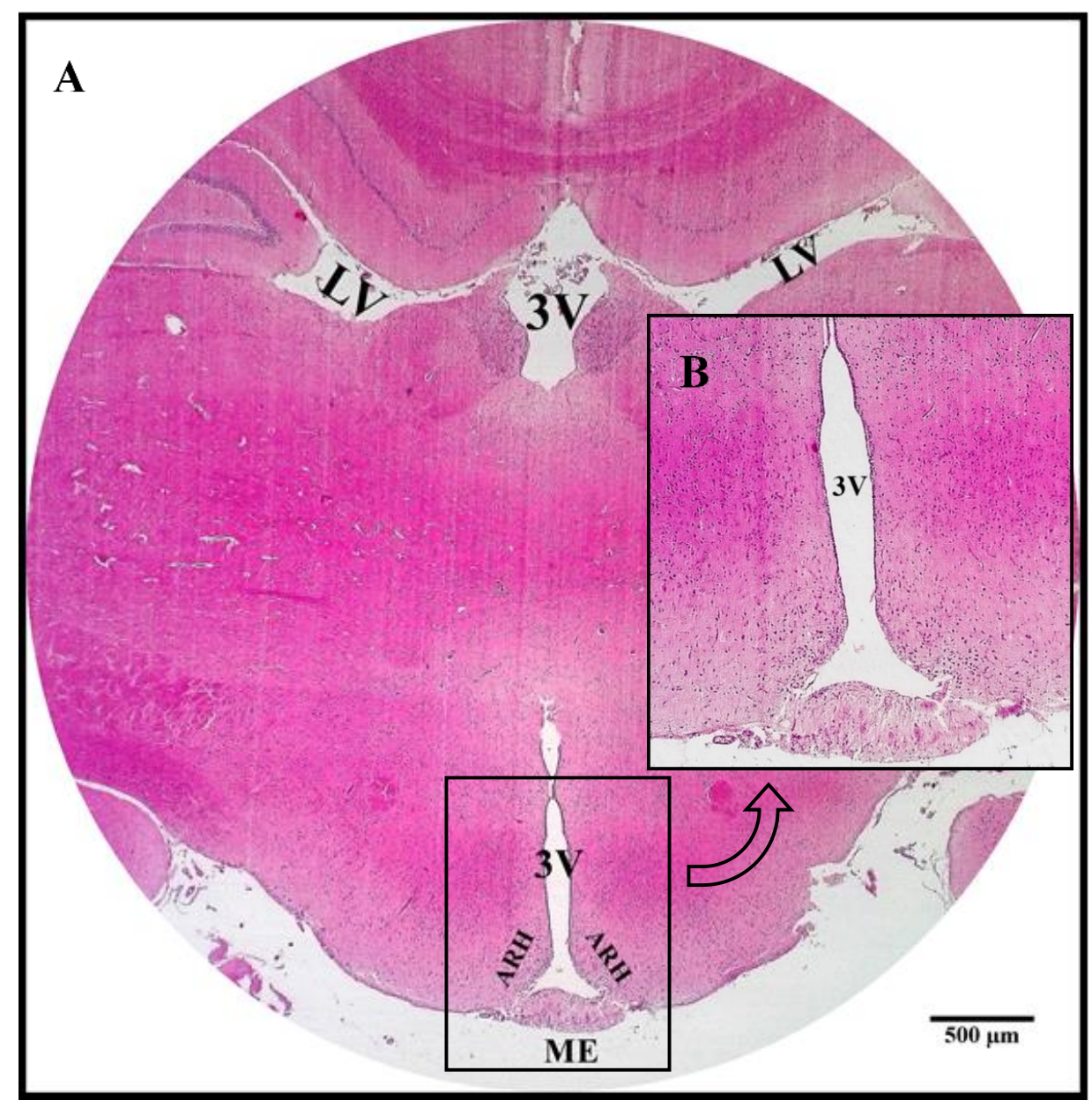

Figure 1. ME lining of ependymal cells in rat. Coronal sections. H. \& E. stain. (A) 40X. (B) 100X. $3 V: 3^{\text {rd }}$ ventricle. LV: lateral ventricle. ME: median eminence. ARH: arcuate hypothalamic nucleus 


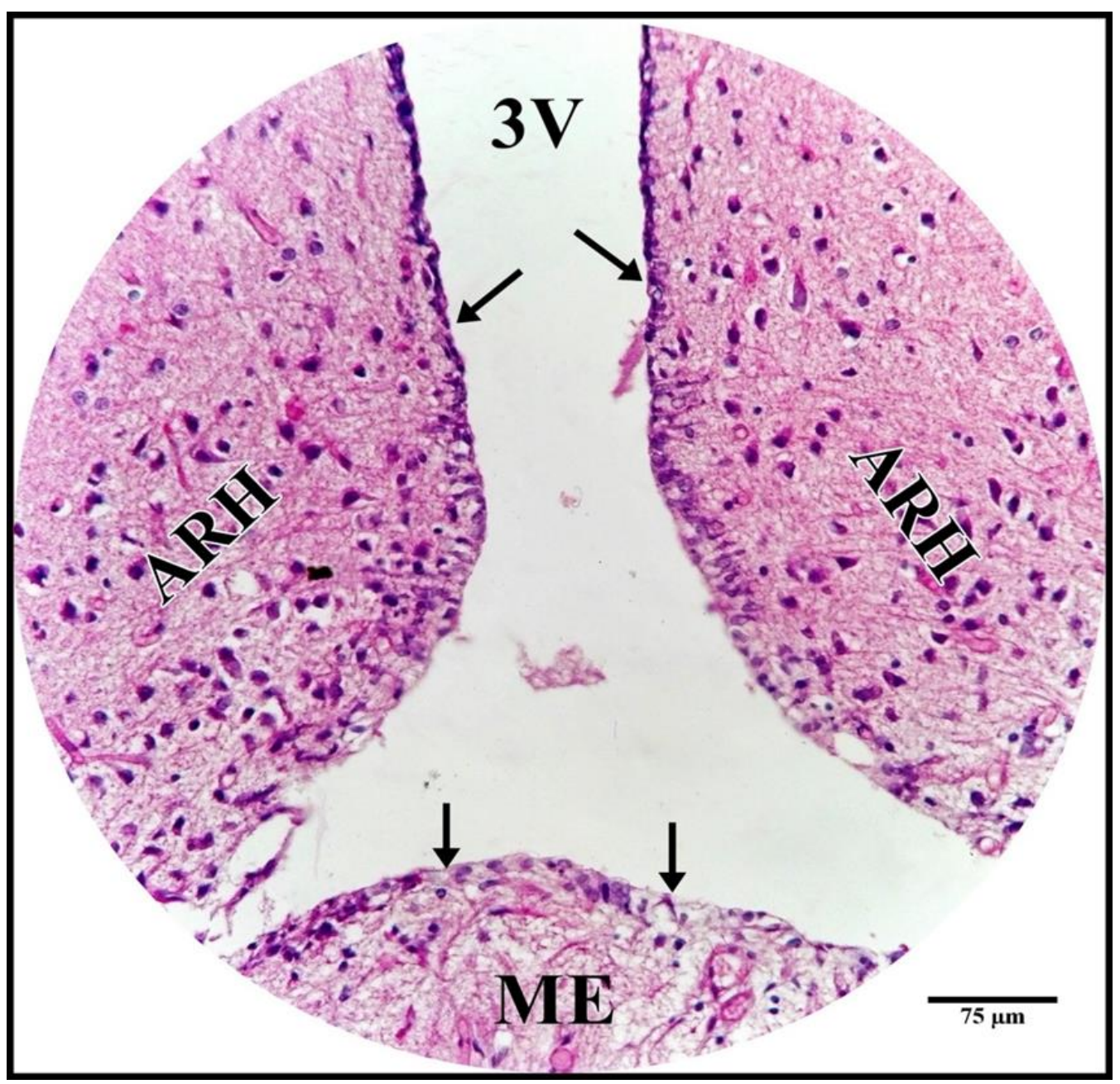

Figure 2. Ependymal lining of the 3rd ventricle walls (arrows). H. \& E. stain. 400X. 3V: $3^{\text {rd }}$ ventricle. ME: median eminence. ARH: arcuate hypothalamic nucleus

\section{Sulcus medianus organum}

The SMO was seen as a median longitudinal cleft in the rostral part of the floor of 4th ventricle. This furrow was lined with a single layer of ECs except at the deepest part of the furrow where a double layer of these cells was observed. Their nuclei stained blue-violate and the cytoplasm stained pink with H. \& E. stain (figures 3-5).

\section{Immunofluorescence labelling} Median eminence

Anti-ZO1 immunolabelling was seen as green fluorescence surrounding tanycytes of the ME.
This labelling of TJs was clearly seen on the apical surface and lateral borders of these tanycytes (figures 6 and 8). An internal negative control is seen in figures 7 and 9 .

\section{Sulcus medianus organum}

Findings of TJs labelling in ECs of the SMO were similar to those seen in tanycytes of the ME. This labelling of TJs was clearly seen on the apical surface and lateral borders of these tanycytes-like cells (figures 10 and 11). An internal negative control is seen in figure 12 . 


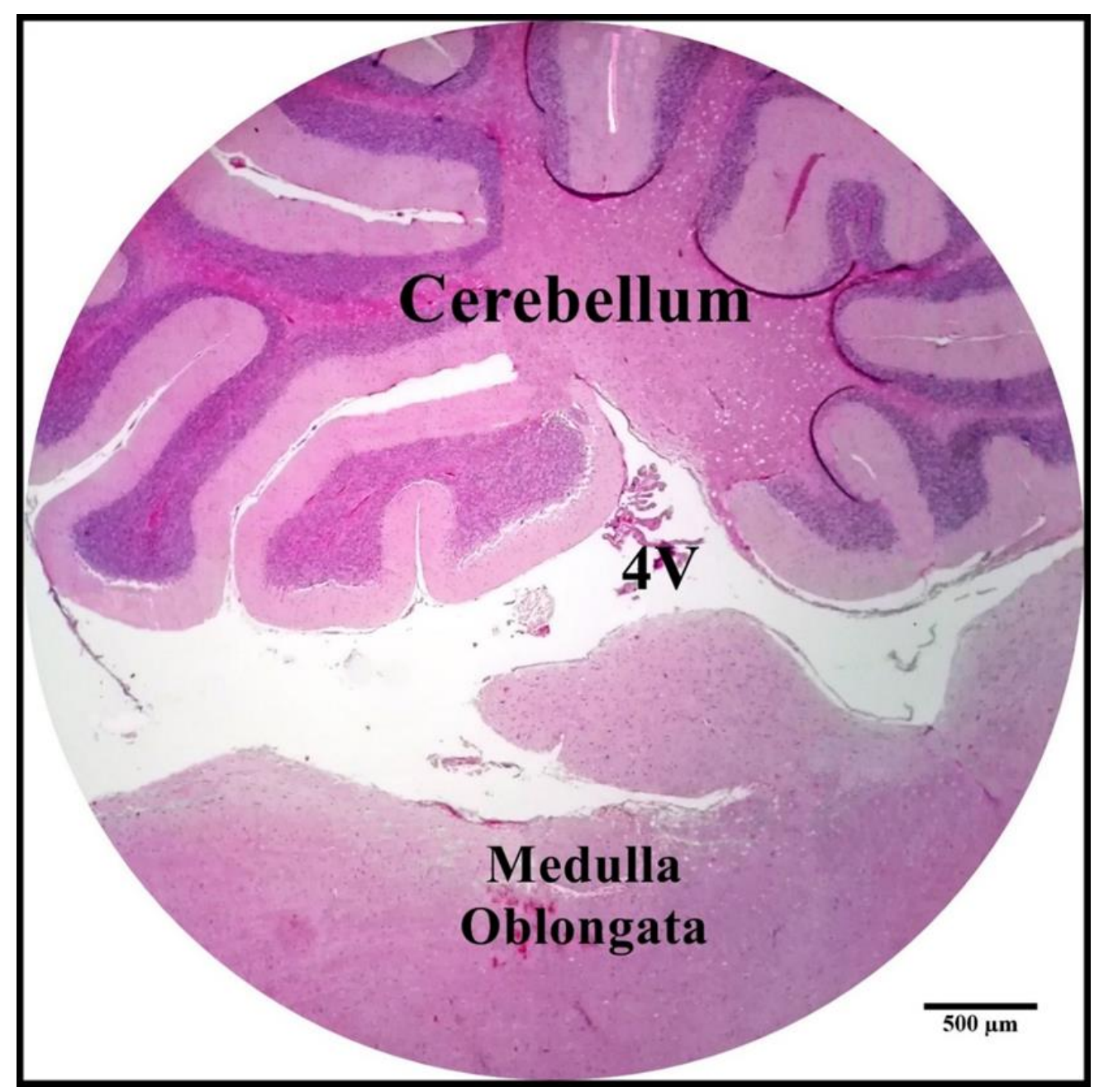

Figure 3. Sagittal section through the $4^{\text {th }}$ ventricle (4V) and SMO (arrows). H. \& E. stain. $40 X$

\section{Controls}

Positive controls for TJs between cells of renal tubules were labelled with ZO1 antibodies (figure 13). Negative controls were prepared by following the same immunohistochemical labelling procedure except for the omission of the primary antibodies (figure 14).

\section{Discussion}

Morphological considerations with H. \& E. stain

\section{Median eminence}

The neurohypophysis is organized into three parts, the ME (infundibulum), the infundibular stem, and the neural lobe (infundibular process). The neurohypophysis contains tanycytes and pituicytes which are specialized glial cells besides nerve terminals and vessels (21).

The ME is considered to be one of the CVOs in the brain that is located in the wall of the $3^{\text {rd }}$ ventricle where tanycytes have been identified and the morphology of these cells has been thoroughly explored by means of photonic observations as well as by TEM and SEM electron microscopy ${ }^{(22)}$.

In this study, examination of sections stained with H. \& E. under light microscope showed cuboidal or irregular cells lining the floor and walls of the $3^{\text {rd }}$ ventricle where cilia were difficult to be identified. Akmayev (23) reported that the floor and ventrolateral walls of the $3^{\text {rd }}$ ventricle were characterized by tanycytic ependymal cells with intimate topographical relationships to hypothalamic neurons and to 
blood vessels of hypothalamus and pituitary. Also, Petrov et al. ${ }^{(24)}$ reported that ependyma at the ME that form the floor of the $3^{\text {rd }}$ ventricle, immediately caudal to the optic chiasm, were irregular in shape (generally flattened) and lack cilia.

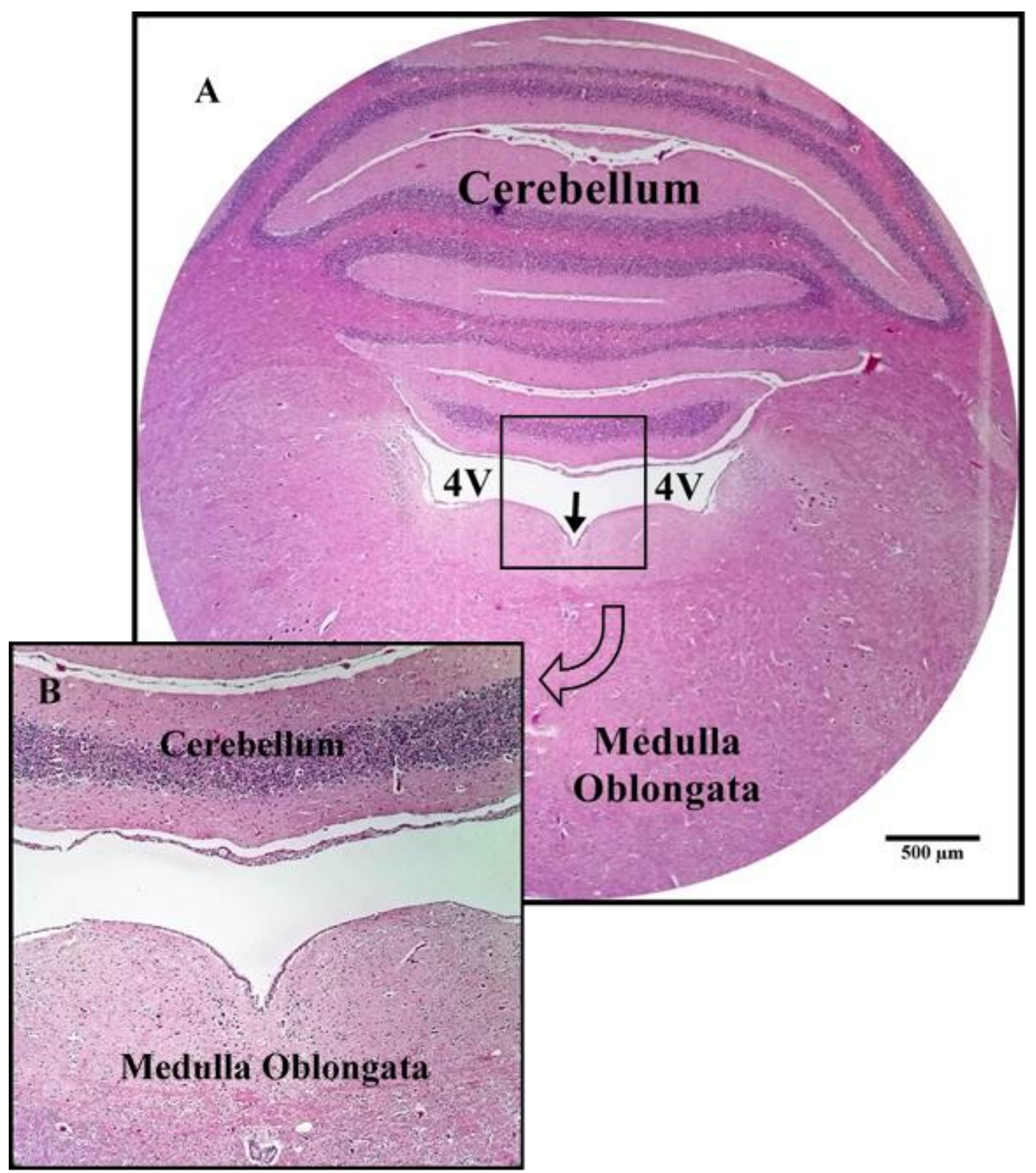

Figure 4. Coronal section of the floor of the 4th ventricle $(4 \mathrm{~V})$ at the region of SMO (arrow). H. \& E. stain. (A) 40X. (B) $100 X$ 


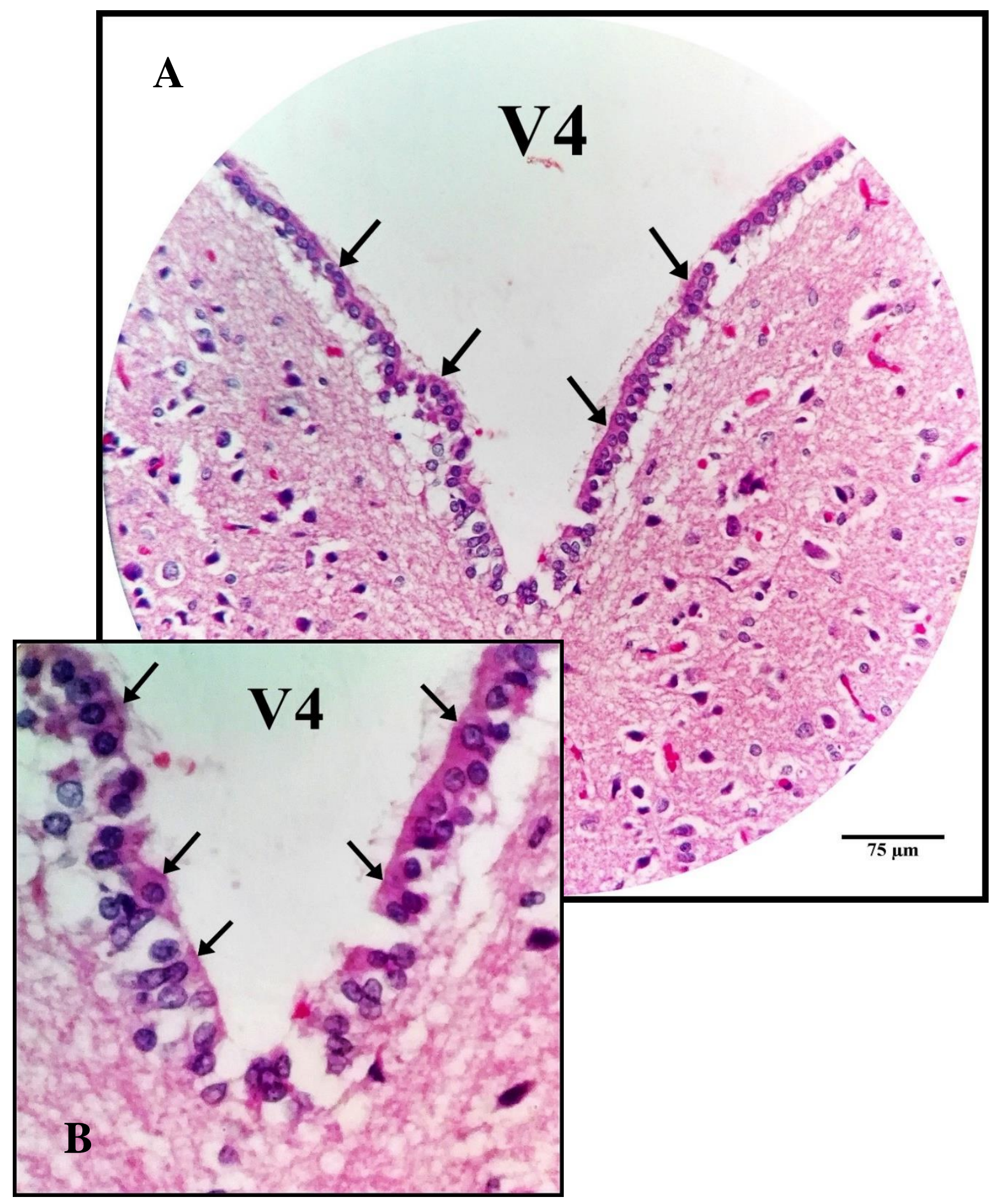

Figure 5. Coronal section of the floor of the $4^{\text {th }}$ ventricle $(4 \mathrm{~V})$ at the region of SMO. Ependymal cells (arrows) line the region of SMO. The median sulcus is lined with a single layer of ependymal cells (arrows). The deepest part of the sulcus shows two layers of cells similar to ependymal cells elsewhere in the walls of the cerebral ventricles. H. \& E. stain. (A) 400X. (B) 1250X SMO: sulcus medianus organum 


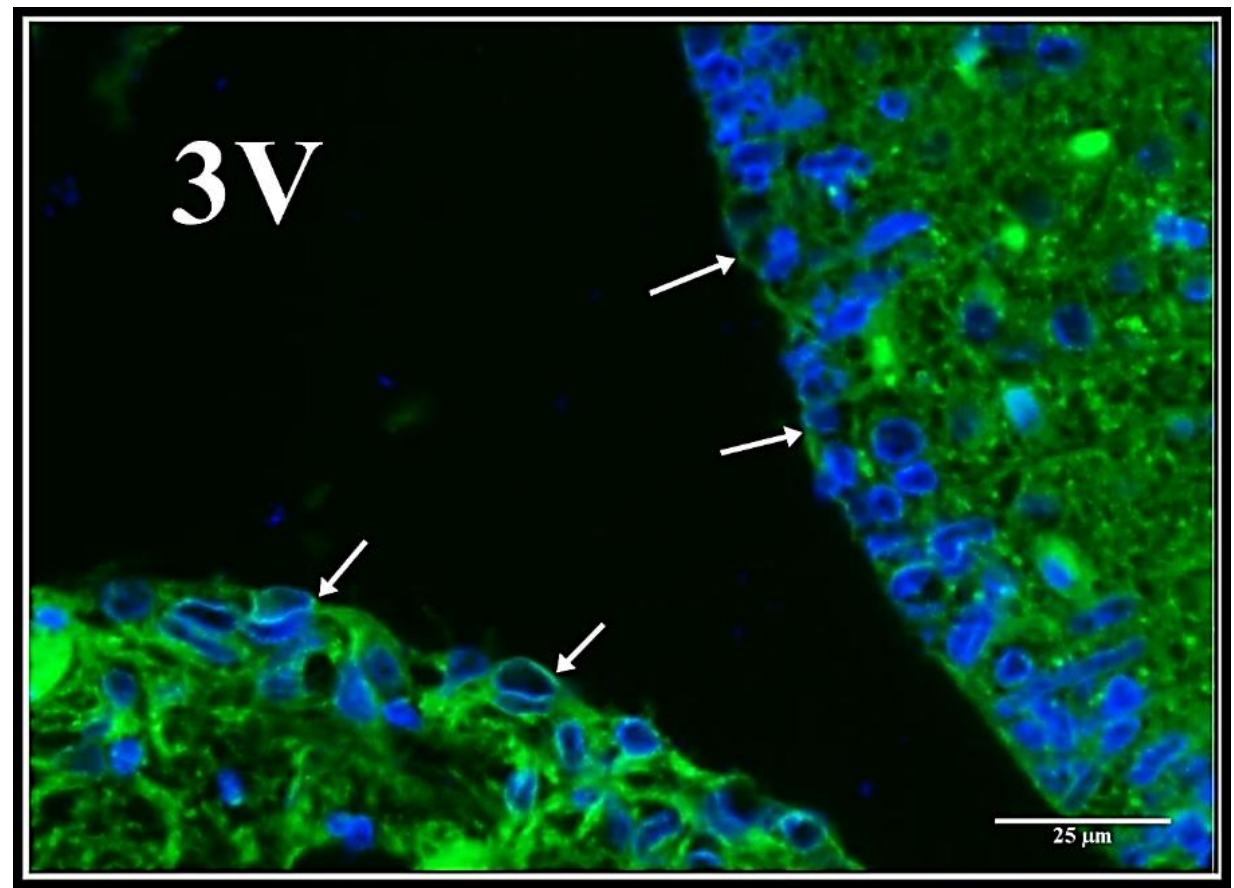

Figure 6. Coronal section at the ME showing TJs as green fluorescence around tanycytes (arrows). DAPI nuclear counterstaining appears as blue fluorescence.3V: $3^{\text {rd }}$ ventricle. $400 \mathrm{X}$

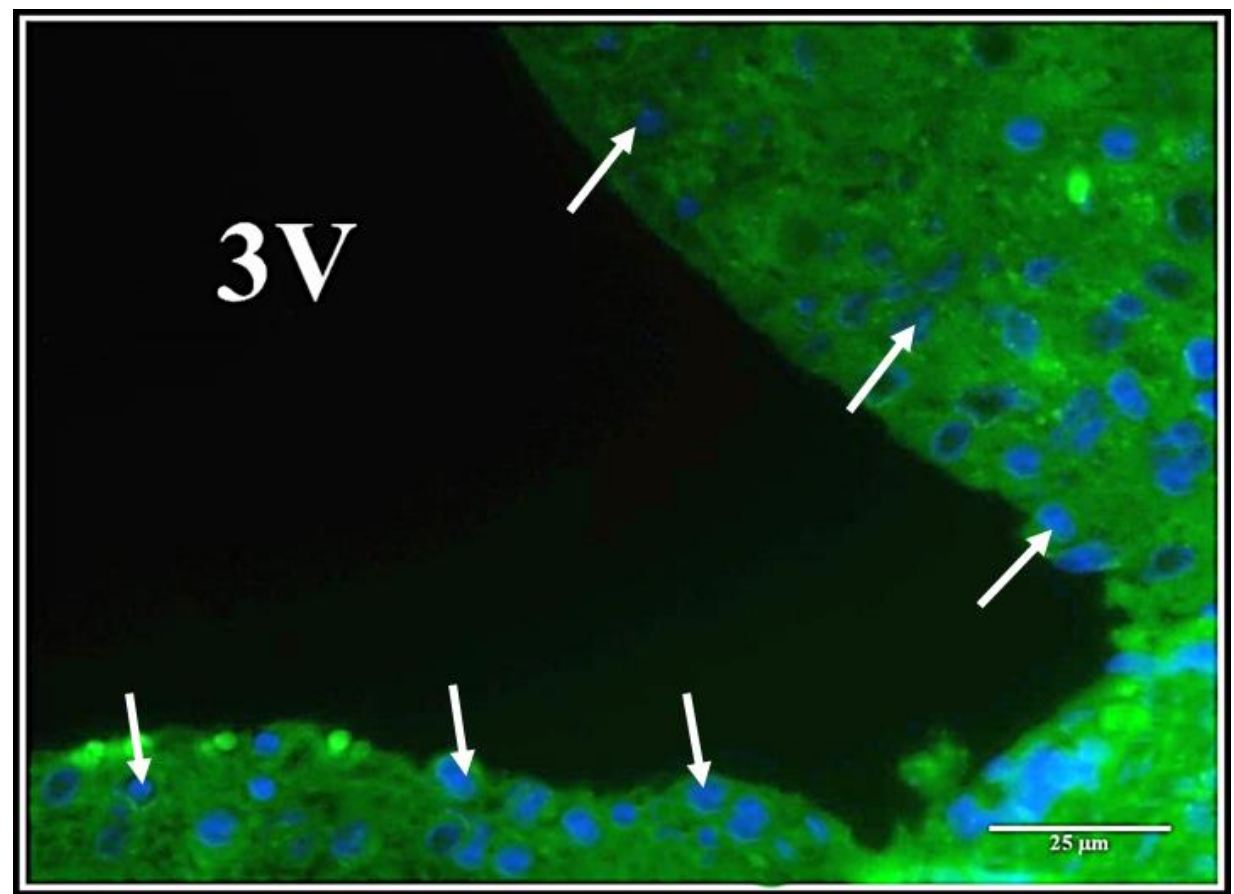

Figure 7. Coronal section at the region of the ME showing ZO1 FITC internal negative control. No labelling is seen along tanycytes of the 3rd ventricle ependymal lining. DAPI nuclear counterstaining is seen as bright blue fluorescence along the nuclei of 3 rd ventricle ependyma (arrows). 3V: $3^{\text {rd }}$ ventricle. 400X 


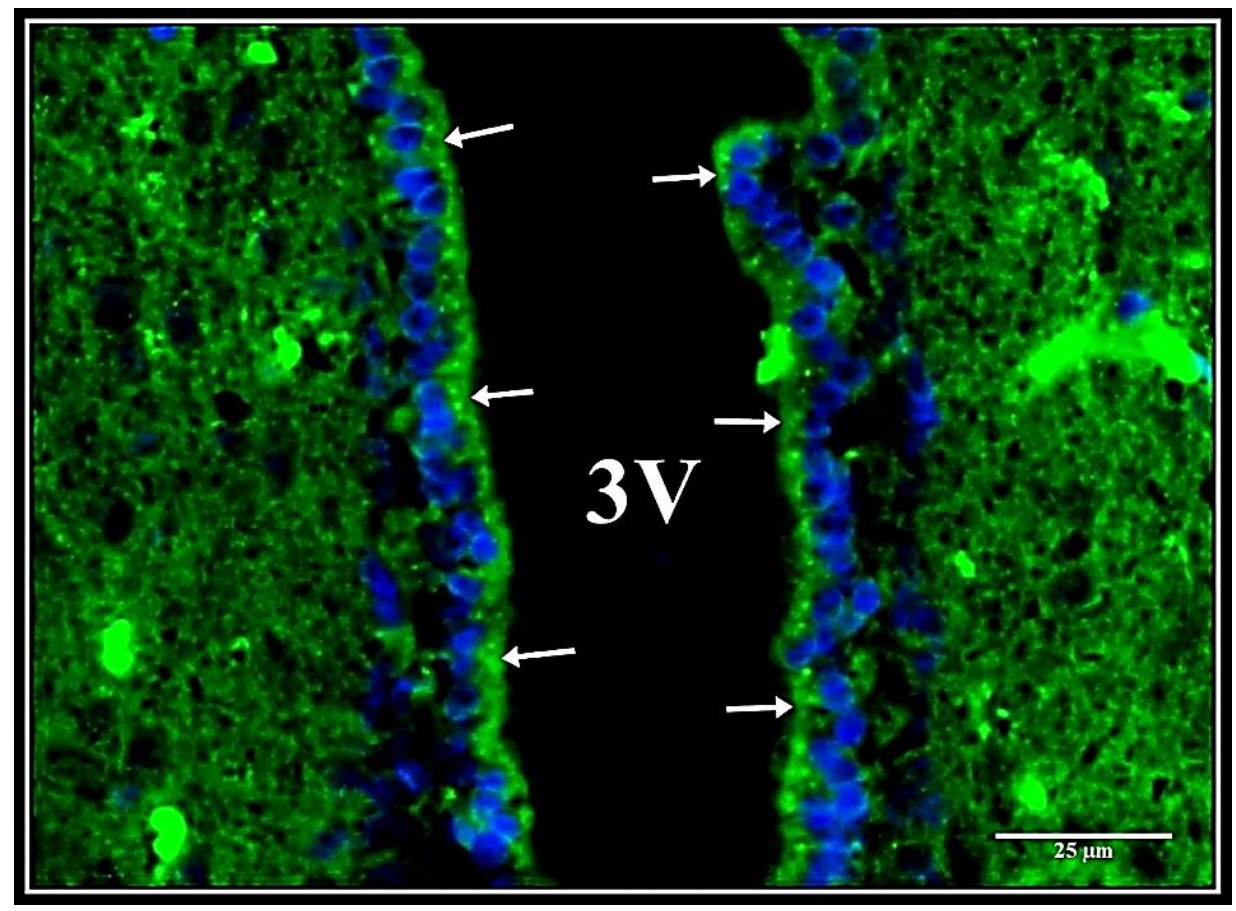

Figure 8. Coronal section showing TJs as green fluorescence around tanycytes of the ME (arrows). TJs are seen on the apical surface and borders of these cells. DAPI nuclear counterstaining is seen as blue fluorescence. $3 \mathrm{~V}: 3^{\text {rd }}$ ventricle. $400 \mathrm{X}$

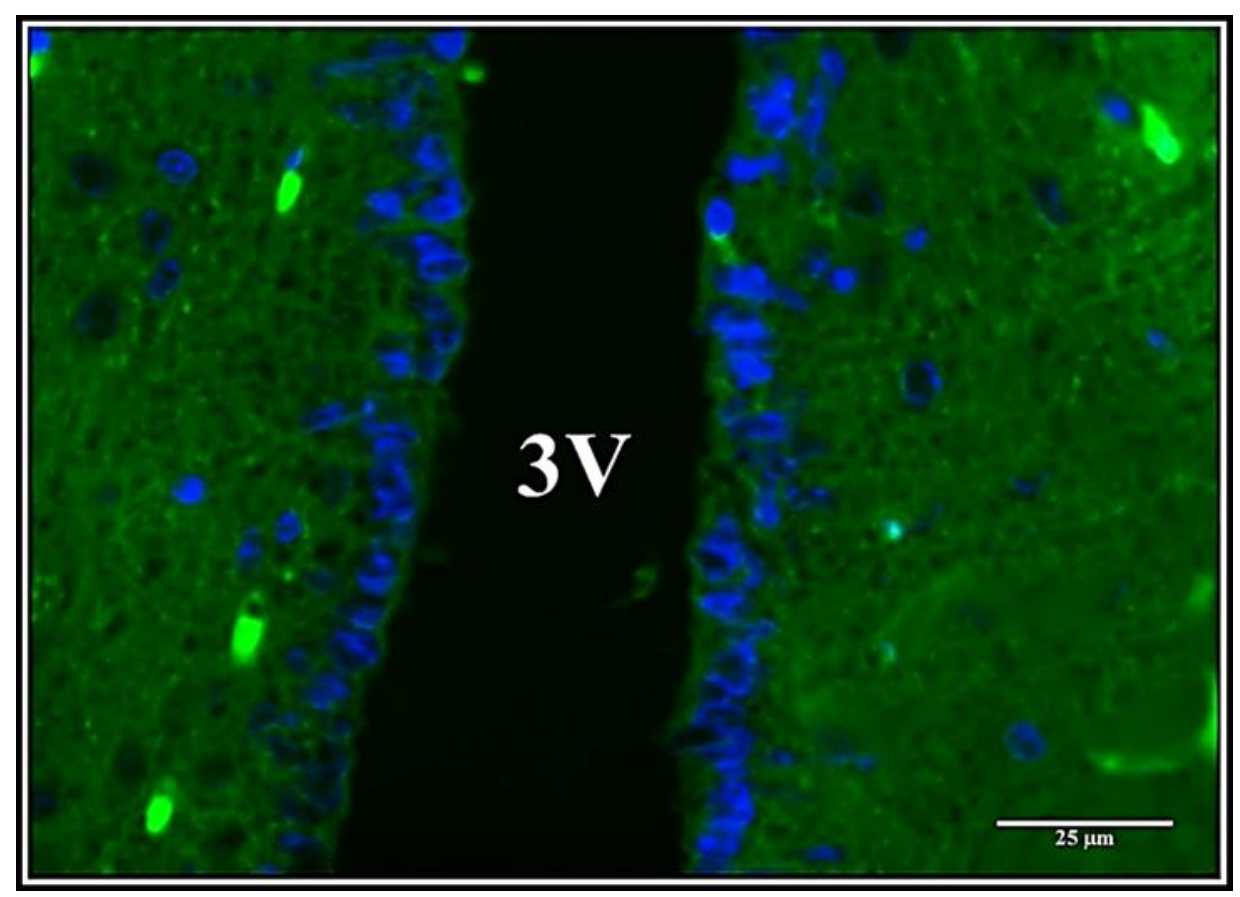

Figure 9. Coronal section at the region of the ME showing ZO1 FITC internal negative control. No labeling is seen along tanycytes of the 3rd ventricle ependymal lining. DAPI nuclear counterstaining is seen as bright blue fluorescence along the nuclei of 3 rd ventricle ependyma (arrows). 3V: $3^{\text {rd }}$ ventricle. $400 \mathrm{X}$ 


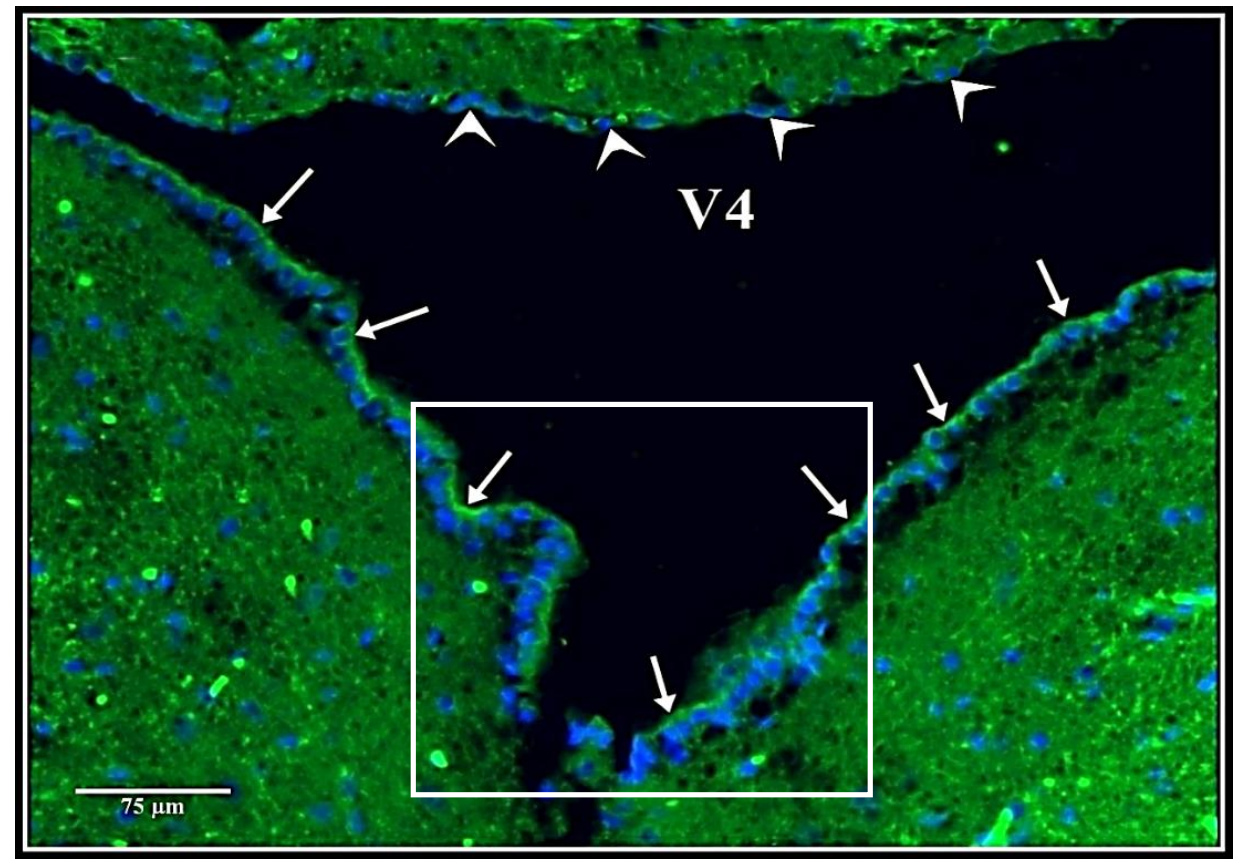

Figure 10. Coronal section showing TJs as green fluorescence around tanycytes of the SMO (arrows). TJs are seen on the apical surface and borders of these cells. DAPI nuclear counterstaining is seen as blue fluorescence. The ependymal cells of roof are negative with ZO1 (head arrows). $4 \mathrm{~V}: 4^{\text {th }}$ ventricle. $400 \mathrm{X}$

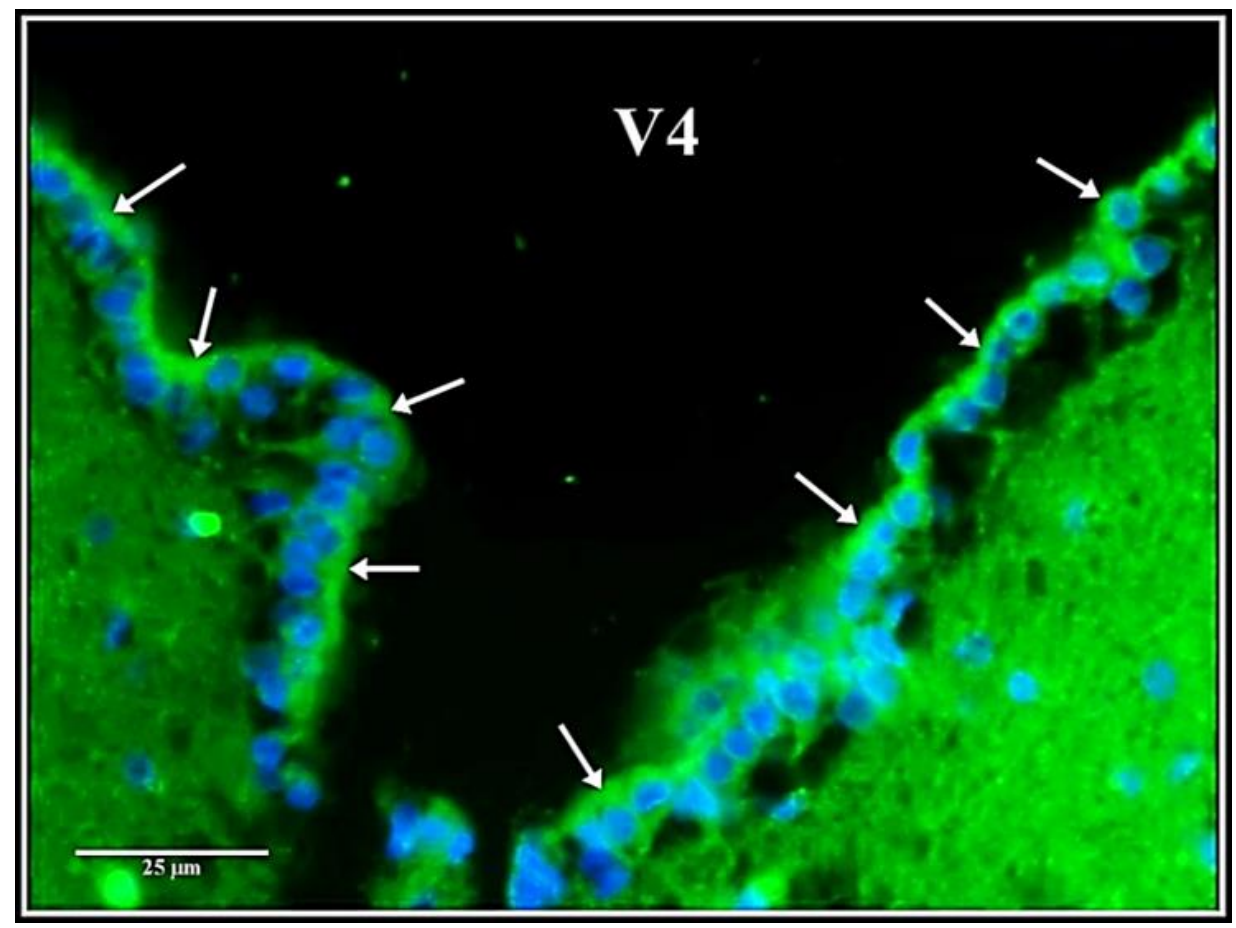

Figure 11. Higher magnification of the inset shown in figure 10. TJs between tanycytes of the SMO are seen as green fluorescence between the cells and on their apical surfaces (arrows). DAPI nuclear counterstaining shows cells nuclei as bright blue fluorescence. $4 \mathrm{~V}: 4^{\text {th }}$ ventricle $630 \mathrm{X}$ 


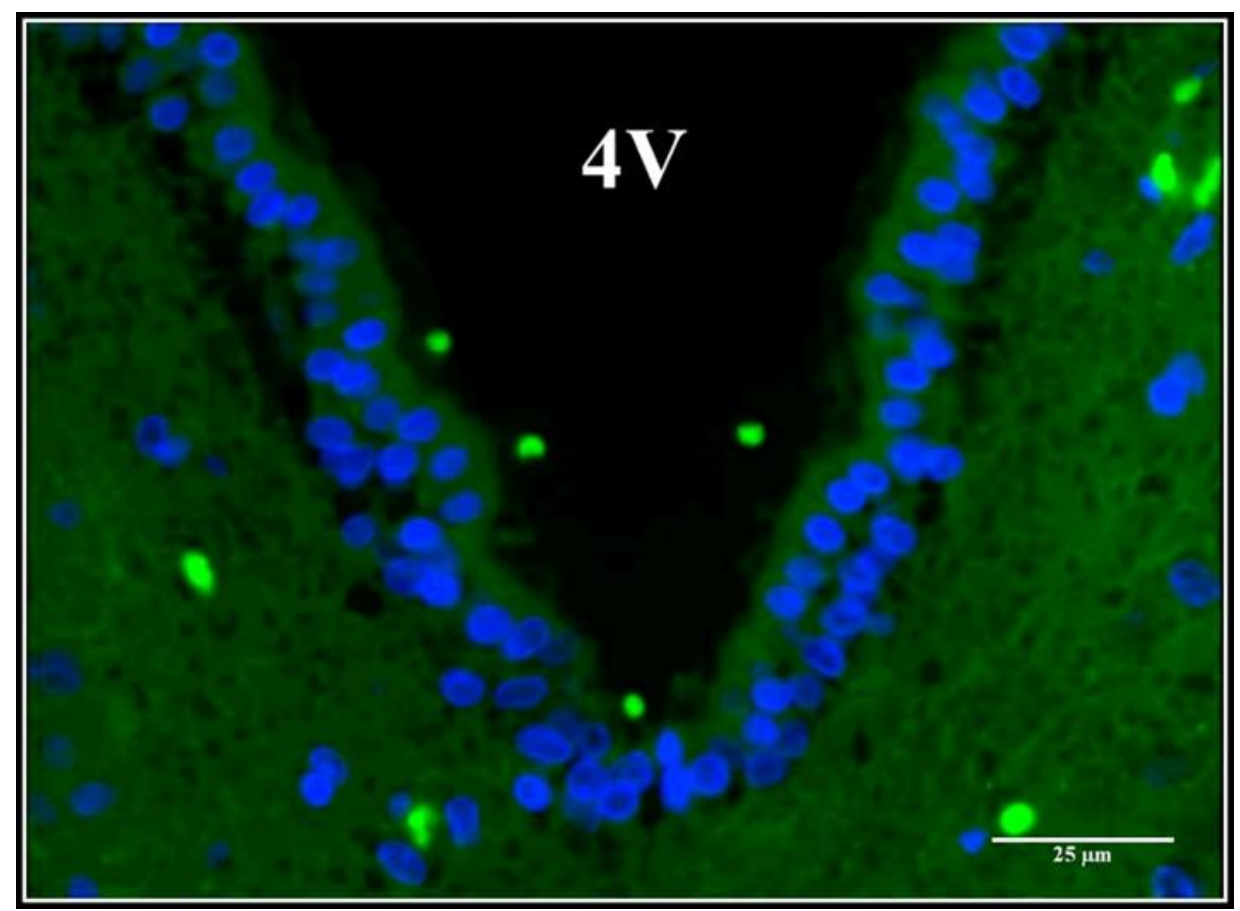

Figure 12. Coronal section at the region of the SMO showing ZO1 FITC internal negative control. No labelling is seen along tanycytes of the 4th ventricle ependymal lining. DAPI nuclear counterstaining is seen as bright blue fluorescence along the nuclei of 4 th ventricle ependyma (arrows). 4V: $4^{\text {th }}$ ventricle. 200X

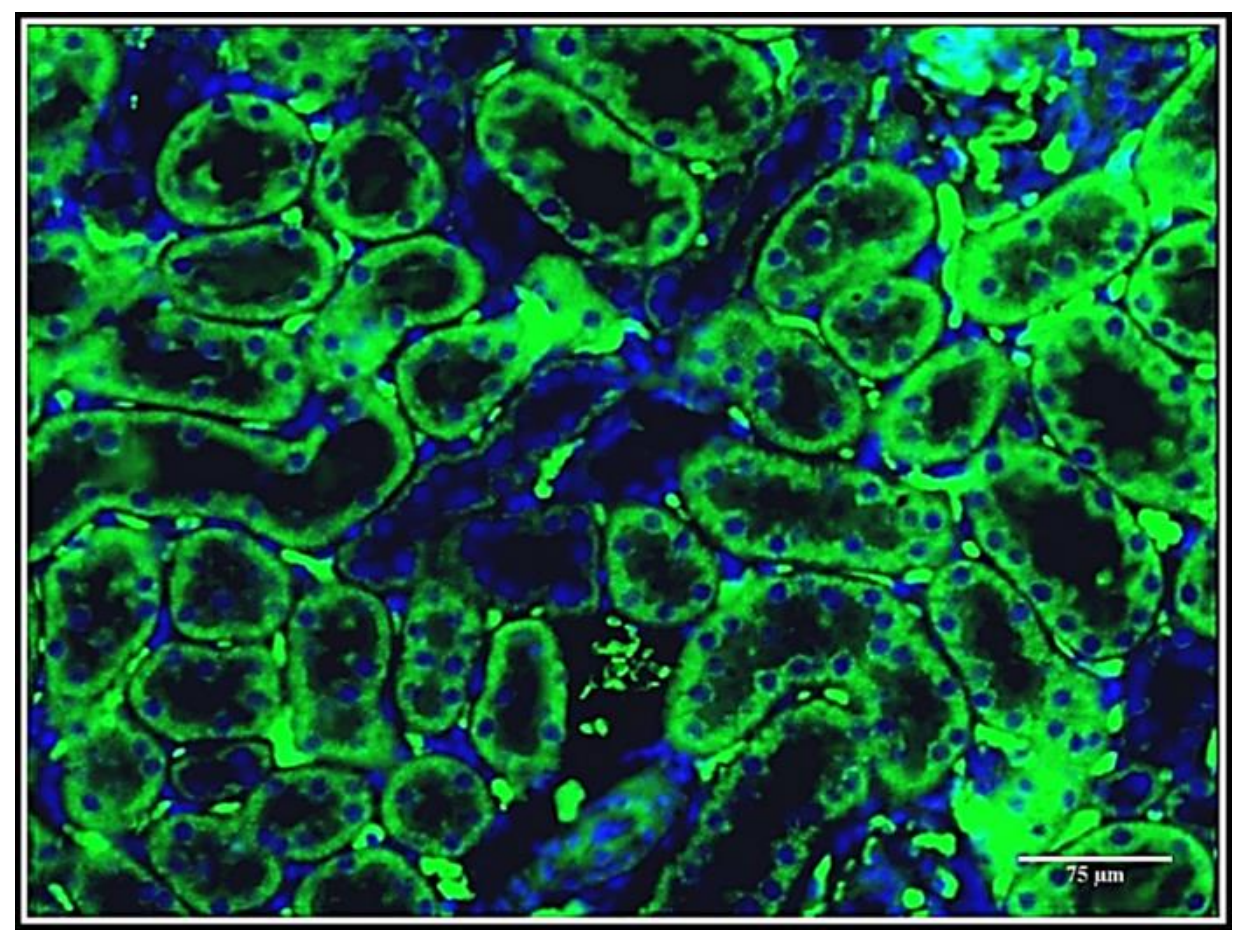

Figure 13. ZO1 positive control in kidney section. Renal tubules show intense green immunofluorescence at TJs between their cells. DAPI nuclear counterstaining is seen as bright blue fluorescence at cell nuclei. 200X 


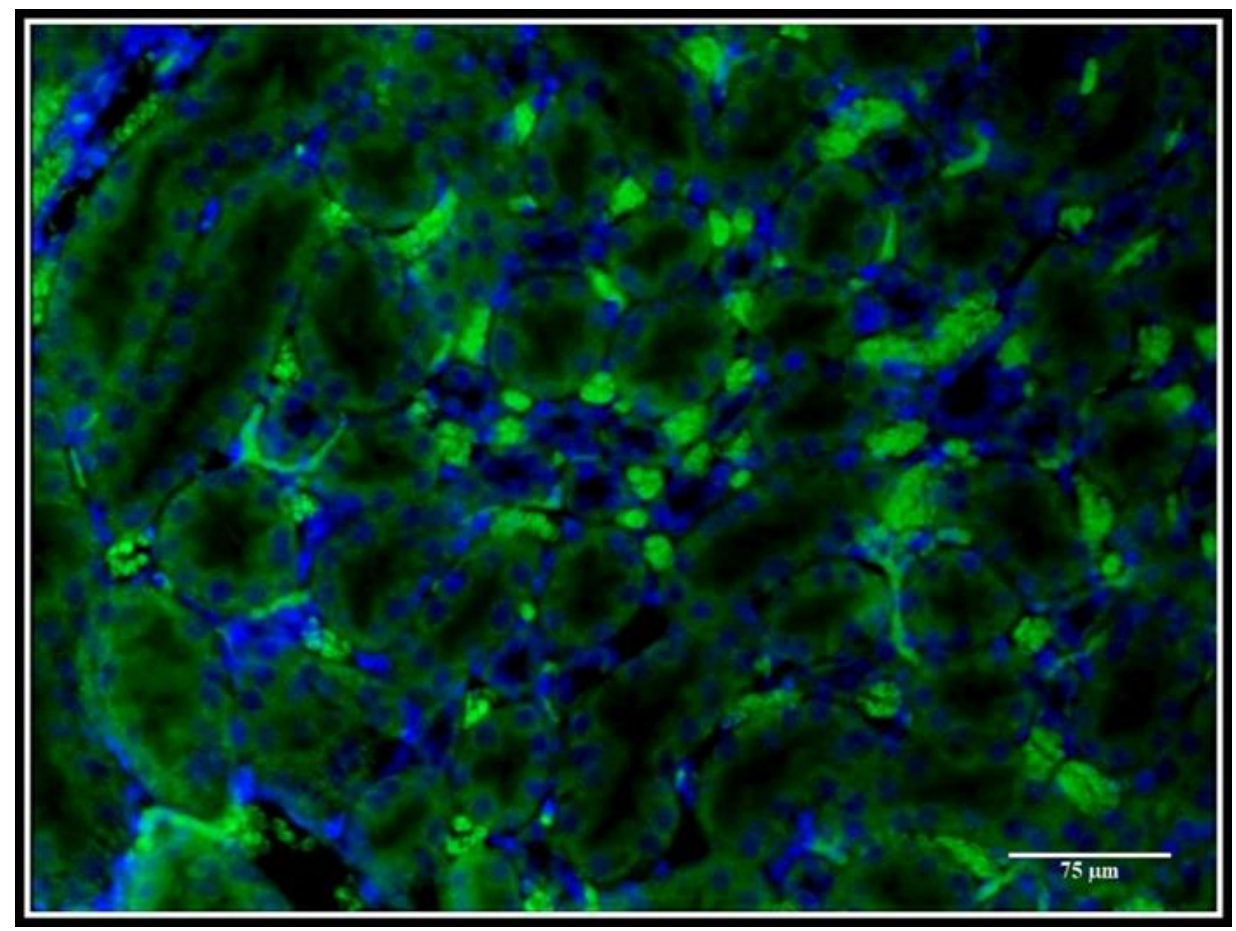

Figure 14. ZO1 negative control in kidney section. Renal tubules do not show TJs immunofluorescent labeling between their cells. DAPI nuclear counterstaining is seen as bright blue fluorescence at cell nuclei. 200X

\section{Sulcus medianus organum}

On light microscopic examination, the epithelium of the SM is pseudostratified with the apical surface of the cells is covered with microvilli; only a few cilia clumps are present (18). Most literatures investigate the caudal part of the SM where the AP is framed by processbearing ECs that connect the ventricular and fenestrated vessels compartments, as portrayed in the ME ${ }^{(25)}$. Researchers, however, did not elaborate on the rostral part of the SM where little attention is paid for the presence of the SMO as one of the CVOs.

Examination with H. \& E. stain showed aligned cuboidal or short columnar cells each with a single round nucleus and no identifiable cilia at their surfaces that line the floor of 4 th ventricle. It is interesting to note that ependymal cells at the depth of the SM in the region of the SMO were seen to be "crowded" in 2-3 layers compared to the single layer ependyma on the MS banks and the floor of the $4^{\text {th }}$ ventricle. This condensation of cells at the SMO may be due to the presence of supraependymal cells on the ventricular aspect of ependyma CVOs ${ }^{(18)}$, or it can be a reflection of the presence of tanycytes or tanycyte-like cells in the region of the SMO.

\section{Immunohistochemical characterization of TJs complexes at tanycytes}

Mullier et al. (6) studied the expression and distribution of important three tight junctional proteins which have essential functional roles in CNS diffusion barriers. These proteins are the ZO1, occludin, and claudin1. ZO1 and occludin immunolabeling was detected at the cells that line the 3rd ventricle and the AP of the $4^{\text {th }}$ ventricle, in other words, those specialized ECs forming the ventricular walls of the CVOs ${ }^{(25)}$.

Since these CVOs lack an endothelial BBB, they serve neurohemal or neurosecretory functions. Capillaries within the CVOs are fenestrated allowing free diffusion of proteins and solutes between the blood and the CVOs. Specialized ECs (tanycytes), which connect by TJs, form a complex network that seal the CNS from the CVOs, creating a distinct BCSFB ${ }^{(26)}$. 
The TJs protein ZO1 is expressed in the special ECs of the CVOs as opposed to the fenestrated endothelial cells suggesting that the barrier has been shifted from the vascular to the ventricular side (27).

\section{Inspection of Immunofluorescence Reaction in the ME}

The ME of the hypothalamus is one such CVO that typically contains a rich capillary plexus with a fenestrated endothelium (28). It also contains tanycytes that constitute the specialized ependyma-glial cellular sheet that lines the floor and the basolateral walls of the third ventricle. A dominant feature of tanycytes is their marked polarization: tanycyte cell bodies are located in the ventral border of the 3rd ventricle, but they also send processes to the vascular walls, where they make contact through "end feet" specializations (29).

In tanycytes located at the ME, previous studies showed that ZO1 immunoreactivity was organized around the cell bodies in a continuous belt, giving rise to a honeycomblike shape. In contrast, tanycytes lining the region of the ventricle adjacent to the arcuate hypothalamic nucleus exhibited a diffuse pattern of ZO1 and occludin immunoreactivity in the apical region of the cells. Similar to tanycytes of the $M E$, an organized pattern of ZO1 and occludin labelling was observed in ECs dorsal to the arcuate hypothalamic nucleus ${ }^{(6)}$. In this study, it could demonstrated that immunofluorescent labelling for TJs and AJs between ECs lining the $3^{\text {rd }}$ ventricle at the region of the ME. This detection of TJs with rabbit anti-ZO1 primary antibodies conjugated with FITC was used as an internal control to validate the results of immunofluorescent labelling of ECs at the region of the SMO. Our results, however, were more in a diffuse rather than a honeycomb pattern, partly because of the fluorescence microscope resolution capacity, and probably because of the type of antibodies used in this study being directly conjugated.

\section{Immunofluorescence labelling of TJs complexes in the region of SMO}

The work of Langlet et al (25), and before that Collins ${ }^{(18)}$ revealed the presence of tanycytelike cells in the floor of $4^{\text {th }}$ ventricle, suggesting that the SMO is another CVO. However, immunohistochemical methods were not used to characterize cell population in that region. In this study, it was aimed to label ECs in the MS with anti-ZO1 antibodies to explore TJs complexes between these cells.

Anti-ZO1 immunolabeling in the SMO region was confined to its cell lining, sparing other cells in the ependymal roof of the $4^{\text {th }}$ ventricle. This finding proved that ECS of the SMO contain TJs, which give them special features of tanycytes or tanycyte-like cells and make them different from the remaining ependyma of the $4^{\text {th }}$ ventricle.

In addition, cells in the depth of the MS at the SMO region showed higher intensity of immunofluorescence to the examining eye. This may support our observation with H. \& E. staining that ECs in the depth of the furrow were arranged in more than one layer, leading to emission of more fluorescence than the single-layered ependyma of the $4^{\text {th }}$ ventricle.

In context of the aforementioned observations, this study suggests that the presence of tanycytes in the region of the SMO could explain the reason beyond the existence of the hypothesized CVO at this location as it can bridge the gap between the $A P$ and the rostrally located CVOs, i.e., on either side of the cerebral aqueduct, where non-neuronal signal transmission may occur through CSFcontacting tanycytes that reach the deeply seated brainstem nuclei.

\section{Acknowledgments}

Thanks to Al-Nahrain University, College of Medicine, and Department of Human Anatomy to provide the facilities and laboratories for the completion of this work.

\section{Author contribution}

Ahmed: collection, assembly and interpretation of data, manuscript writing; Dr. Al-Kaabi: conception and design, interpretation of data, manuscript writing; Dr. Al-Marsoummi: 
interpretation of data; Dr. Al-Aubaidy: manuscript writing. All authors have approved the final article.

\section{Conflict of interest}

Authors declare no conflict of interests.

\section{Funding}

No external funding sources.

\section{References}

1. Korr H. Proliferation of different cell types in the brain. Berlin: Springer-Verlag; 1980. p. 72 p. doi: 10.1007/978-3-642-67577-5.

2. Altman J, Bayer SA. Development of the diencephalon in the rat. III. Ontogeny of the specialized ventricular linings of the hypothalamic third ventricle. J Comp Neurol. 1978; 182(5): 9951015. doi: $10.1002 /$ cne.901820513.

3. Bayer SA. Development of the diencephalon in the rat. I. Autoradiographic study of the time of origin and settling patterns of neurons of the hypothalamus. J Comp Neurol. 1978; 182(5): 945-71. doi: $10.1002 /$ cne.901820511.

4. Horstmann E. The fiber glia of selacean brain. Z Zellforsch Mikrosk Anat. 1954; 39(6): 588-617.

5. Rodriguez EM, Blazquez JL, Pastor $F E$, et al. Hypothalamic tanycytes: a key component of brainendocrine interaction. Int Review Cytol. 2005; 247: 89-164. doi: 10.1016/S0074-7696(05)47003-5.

6. Mullier A, Bouret SG, Prevot V, et al. Differential distribution of tight junction proteins suggests a role for tanycytes in blood-hypothalamus barrier regulation in the adult mouse brain. J Comp Neurol. 2010; 518(7): 943-62. doi: 10.1002/cne.22273.

7. Szathmari A, Jouvet A, Mottolese $C$, et al. Anatomical, molecular and pathological consideration of the circumventricular organs. Neurochirurgie. 2015; 61(2): 90-100. doi: 10.1016/j.neuchi.2013.04.006.

8. Benarroch EE. Circumventricular organs: receptive and homeostatic functions and clinical implications. Neurology. 2011; 77(12): 1198-204. doi: 10.1212/WNL.0b013e31822f04a0.

9. Duvernoy HM, Risold PY. The circumventricular organs: an atlas of comparative anatomy and vascularization. Brain Res Rev. 2007; 56(1): 119-47. doi: 10.1016/j.brainresrev.2007.06.002.

10. Morita S, Miyata S. Different vascular permeability between the sensory and secretory circumventricular organs of adult mouse brain. Cell Tissue Res. 2012; 349(2): 589-603. doi: 10.1007/s00441-012-1421-9.

11. Willis CL, Garwood CJ, Ray DE. A size selective vascular barrier in the rat area postrema formed by perivascular macrophages and the extracellular matrix. Neuroscience. 2007; 150(2): 498-509. doi: 10.1016/j.neuroscience.2007.09.023.

12. Maolood N, Meister B. Protein components of the blood-brain barrier (BBB) in the brainstem area postrema-nucleus tractus solitarius region. J Chem Neuroanat. 2009; 37(3): 182-95. doi: 10.1016/j.jchemneu.2008.12.007.

13. Miyata S. New aspects in fenestrated capillary and tissue dynamics in the sensory circumventricular organs of adult brains. Front Neurosci. 2015; 9: 390. doi: 10.3389/fnins.2015.00390.

14. Abbott NJ. Dynamics of CNS barriers: evolution, differentiation, and modulation. Cell Mol Neurobiol. 2005; 25(1): 5-23. doi: 10.1007/s10571-004-1374-y.

15. Langlet F. Tanycytes: a gateway to the metabolic hypothalamus. J Neuroendocrinol. 2014; 26(11): 75360. doi: 10.1111/jne.12191.

16. Wolburg H, Paulus W. Choroid plexus: biology and pathology. Acta Neuropathol. 2010; 119(1): 75-88. doi: 10.1007/s00401-009-0627-8.

17. Tietz S, Engelhardt B. Brain barriers: Crosstalk between complex tight junctions and adherens junctions. J Cell Biol. 2015 ;209(4): 493-506. doi: 10.1083/jcb.201412147.

18. Collins $P$. The sulcus medianus organ in the fourth cerebral ventricle of the rabbit: a previously undescribed circumventricular organ. J Anat. 1989; 162: 185-93.

19. Suvarna SK, Layton C, Bancroft JD. The Hematoxylins and Eosin. In: Bancroft JD, Layton C. (eds.) Bancroft's Theory and practice of histological techniques. $7^{\text {th }}$ ed. China: Churchill Livingstone; 2013. p. 173-88.

20.Shi SR, Liu C, Taylor CR. Standardization of immunohistochemistry for formalin-fixed, paraffinembedded tissue sections based on the antigenretrieval technique: from experiments to hypothesis. J Histochem Cytochem. 2007; 55(2): 105-9. doi: 10.1369/jhc.6P7080.2006.

21. Paxinos $G$. The rat nervous system. $4^{\text {th }}$ ed. Academic Press; 2014. (eBook ISBN 9780080921372).

22. Joly JS, Osório J, Alunni A, et al. Windows of the brain: towards a developmental biology of circumventricular and other neurohemal organs. Semin Cell Dev Biol. 2007; 18(4): 512-4. doi: 10.1016/j.semcdb.2007.06.001

23. Akmayev IG, Fidelina OV, Kabolova ZA, et al. Morphological aspects of the hypothalamichypophyseal system. IV. Medial basal hypothalamus. An experimental morphological study. Z Zellforsch Mikrosk Anat. 1973; 137(4): 493-512. doi: 10.1007/BF00307226.

24. Petrov $T$, Howarth AG, Krukoff TL, et al. Distribution of the tight junction-associated protein ZO-1 in circumventricular organs of the CNS. Brain Res Mol Brain Res. 1994; 21(3-4): 235-46. doi: 10.1016/0169328X(94)90254-2.

25. Langlet F, Mullier A, Bouret SG, et al. Tanycyte-like cells form a blood-cerebrospinal fluid barrier in the circumventricular organs of the mouse brain. The J Comp Neurol. 2013; 521(15): 3389-405. doi: 10.1002/cne.23355.

26. Engelhardt B, Sorokin L. The blood-brain and the blood-cerebrospinal fluid barriers: function and 
dysfunction. Sem Immunopathol. 2009; 31(4): 497511. doi: 10.1007/s00281-009-0177-0.

27. Vorbrodt AW, Dobrogowska DH. Molecular anatomy of intercellular junctions in brain endothelial and epithelial barriers: electron microscopist's view. Brain Res, Brain Res Rev. 2003; 42(3): 221-42. doi: 10.1016/S0165-0173(03)00177-2.

28. Schulz M, Engelhardt $B$. The circumventricular organs participate in the immunopathogenesis of experimental autoimmune encephalomyelitis. Cerebrospinal Fluid Res. 2005; 2: 8. doi: $10.1186 / 1743-8454-2-8$.
29. Prevot V. Glial-neuronal-endothelial interactions are involved in the control of $\mathrm{GnRH}$ secretion. J Neuroendocrinol. 2002; 14(3): 247-55. doi: 10.1046/j.0007-1331.2001.00772.x.

Correspondence to Dr. Muthanna A. Al-Kaabi E-mail: muthanna.alkaabi@colmedalnahrain.edu.iq Received $10^{\text {th }}$ Nov. 2016 Accepted $12^{\text {th }}$ Jan. 2017 